\title{
THE ADVANTAGES CHRYSOMELID BEETLES SECURE BY CONCEALING THEIR EGGS.
}

\author{
By Robert W. Hegner,
}

Zoölogical Laboratory of the University of Michigan, Ann Arbor, Michigan.

It is obvious to everyone that eggs that are concealed will be more likely to escape destruction than those that are laid in open situations and hence easily seen by predatory animals. There is good reason for believing, however, that in the case of those chrysomelid beetles that lay their eggs on the under surface of leaves, there are other factors involved which make concealment only one of the advantages thus secured. It is the general habit of insects as well as many other animals to hide their eggs. Often this results in their development in the dark. Large numbers of animal eggs develop normally in the dark since those that pass through the embryonic period within the body of an opaque parent or are surrounded by opaque envelopes are effectively shielded from the light. Many experiments have been performed with the eggs of a large number of animals in order to test the influence of darkness upon embryonic development, but the general conclusion has been reached that the lack of light neither retards nor accelerates growth. In beetles' eggs the chorion allows the penetration of light rays and hence the direct rays of the sun must reach the interior of the eggs exposed to them.

So far as I know no one has determined the reasons why many insects lay their eggs on the under surface of the leaves of plants, rather than on the upper surface. The experiments described in this paper were undertaken with the idea of furnishing data which might assist in explaining this phenomenon. The potato beetle, Leptinotarsa decemlineata, was found to be favorable for this purpose because of the ease of obtaining its eggs and of rearing it in the laboratory. Besides the normal development of the eggs of this beetle is well known.

It was first proved that there is no difference between the upper and lower surfaces of a potato leaf which causes the beetles to prefer the lower surface, since individuals placed in stender dishes in the laboratory laid their eggs on the under surface of the leaves 
as they lay in the dishes regardless of whether this was the upper or under surface in nature.

A series of experiments were then performed in order to determine if direct sunlight is injurious to the developing eggs. These experiments extended over the period from June 11 to June 23, 1914. Fortunately these days were practically cloudless and thus afforded an abundant and uninterrupted supply of sunlight. The details of two experiments will suffice to indicate the nature of the experiments and the conclusions that may be drawn from them.

\section{Experiment I.}

On June 15, fifty batches of potato beetles' eggs were collected at random. Each batch of eggs and that part of the leaf to which it was attached was cut away from the rest of the leaf. Thirtyfive batches were then pinned firmly to a board and the board was placed on top of the laboratory where the rays of the sun would strike the eggs throughout the day. The remaining fifteen batches were pinned to another board, which was placed beside the other but inverted so that the eggs were in the shade at all times. The results are recorded in Table $\mathbf{I}$.

Table I.

\begin{tabular}{c|l|l}
\hline \hline Date. & \multicolumn{1}{|c}{ Sun. } & \multicolumn{1}{c}{ Shade. } \\
\hline June 15 & $\begin{array}{l}\text { 35 batches of eggs } \\
\text { one batch hatching (did not succed) } \\
\text { one batch lost } \\
\text { fune 16 } \\
\text { June 18 } \\
\text { June 19 } \\
\text { June 22 } \\
\text { June 23 }\end{array}$ & $\begin{array}{l}\text { 15 batches of eggs } \\
\text { one batch hatched } \\
\text { three batches hatched } \\
\text { nour batches hatched } \\
\text { none batches hatched } \\
\text { two batches hatched }\end{array}$ \\
\hline
\end{tabular}

As shown in the table all of the fifteen batches placed in the shade under the board hatched. Their ages when collected differed greatly since some of them hatched every day until all of the larvæ had emerged. Those that hatched on the seventh and eighth days (June 22 and 23) must have been fresh when gathered, and their hatching must have been delayed for some reason since the normal hatching period is five to six days. Lack of moisture is 
suggested as the retarding factor since the eggs were in a rather dry place compared with that in which they are usually laid and it has been found that eggs in the laboratory must be kept in a moist atmosphere to insure the emergence of the larvæ.

Of the thirty-five batches placed in direct sunlight none hatched, but eighteen developed up to the hatching point. Twelve batches showed no signs of hatching at the end of the eighth day. Five of the batches were either blown away or destroyed by some animal. The only animals that could possibly be responsible for the disappearance of these eggs were birds or large insects, but whether or not they were responsible was not determined.

\section{EXPERIMENT II.}

On June 15, a beetle just about ready to deposit eggs was placed on a plant in the garden and enclosed by a glass jar. Within two hours she laid a batch of thirty eggs. Part of these were taken to the laboratory where they hatched in six days (June 22). The leaf to which the rest of the eggs were fastened was bent over and held in place so that the rays of sunlight would strike the eggs.

At the end of twenty-four hours four of the control eggs and four of those left on the plant were fixed. Sections of these eggs show that development proceeded in both groups at the same rate and that sunlight had no visible influence upon the development of the eggs subjected to it. Another group of four were taken from the plant at the same time and kept in the laboratory in a moist watch glass. These hatched in the normal period (six days). Sunlight acting upon the fresh eggs for a period of one day had therefore no effect upon the development of these embryos.

The eggs on the plant in the sunlight should have hatched on June 22. On this date the larvæ within them could plainly be seen; they failed to emerge within the next two days when the experiment was concluded.

General Conclusions. These experiments prove that the eggs of the potato beetle in various stages of development are prevented from hatching when kept in direct sunlight, but are not retarded in their development. The non-hatching of these eggs is probably due to partial dessication. The advantage of concealment is not so great therefore as that secured by shielding the eggs from the dessicating properties of sunlight, since the potato beetle 
race would probably persist even if the eggs were not concealed, but would certainly die out if the eggs were laid where sunlight could act upon them.

\title{
TWO NEW ORIENTAL PHORID正.
}

\author{
By J. R. MALLOCh, \\ Urbana, Illinois.
}

Aphiochæta parasitica, sp. nov.

Female: Yellow. Frons slightly darkened towards vertex; antennæ, and proboscis yellow, palpi whitish-yellow. Pleura with a small dark spot below wing base. Dorsum of abdomen brown, each segment with a very narrow yellow posterior marginal line. Legs yellow, mid coxæ with a black spot on their posterior surface; apices of hind femora and dorsal surface of hind tibiæ blackened. Wings clear, veins brownish. Halteres yellow. (This description is drawn from alcoholic specimens. Fresh or dry mounted examples will probably be darker in color.)

Frons slightly longer than broad, the surface with numerous short hairs; postantennal bristles 4 in number, sub-equal in size; first row of bristles convex, the center pair but little below the outer pair and distinctly nearer to center of frons; antennæ normal in size, third joint rounded; arista bare, about one-third longer than length of frons, palpi projecting beyond apex of antenna, not swollen, and with about 8 distinct black bristles; cheek bristled. Mesopleura bare; scuttellum with 4 bristles, the basal pair slightly the weaker. Abdomen almost bare, only a few very weak setulæ present, the segments sub-equal in length. Legs normal; fore tarsi slender; hind femora and tibiæ dilated; the mid tibial setulæ weak; hind femora with a few weak setulæ on the basal half of the ventral surface; hind tibiæ with 10-11 setulæ extending in a series from basal third to apex, which at no part exceed in length one-half the tibial diameter. Costa to about three sevenths the wing length; fringe close, the hairs not exceeding in length twice the diameter of the costal vein, first costal division about 5 times the length of second; third slightly shorter than second; fourth vein gently arcuated, ending distinctly in front of wing tip, slightly recurved.

Male: Similar to female in coloration. Differs in having the frons rather narrower; the lower pair of post-antennals minute, and the upper rather close together; the antennæ larger, the third joint over one-third as large as the eye; the abdomen tapering; the hypopygium slightly exposed, and the anal protuberance very small, with 2 weak apical hairs; the costa reaching to about two-fifths the wing length, the second and third divisions thereof sub-equal, and the fringe more widely spaced.

Length: $\quad 1.75-2.5 \mathrm{~mm}$.

Type: From Heliothis larva, Medan, Sumatra, May, 1912.

Allotype (Male): Same data. Paratypes: Same data. Five specimens in all. 

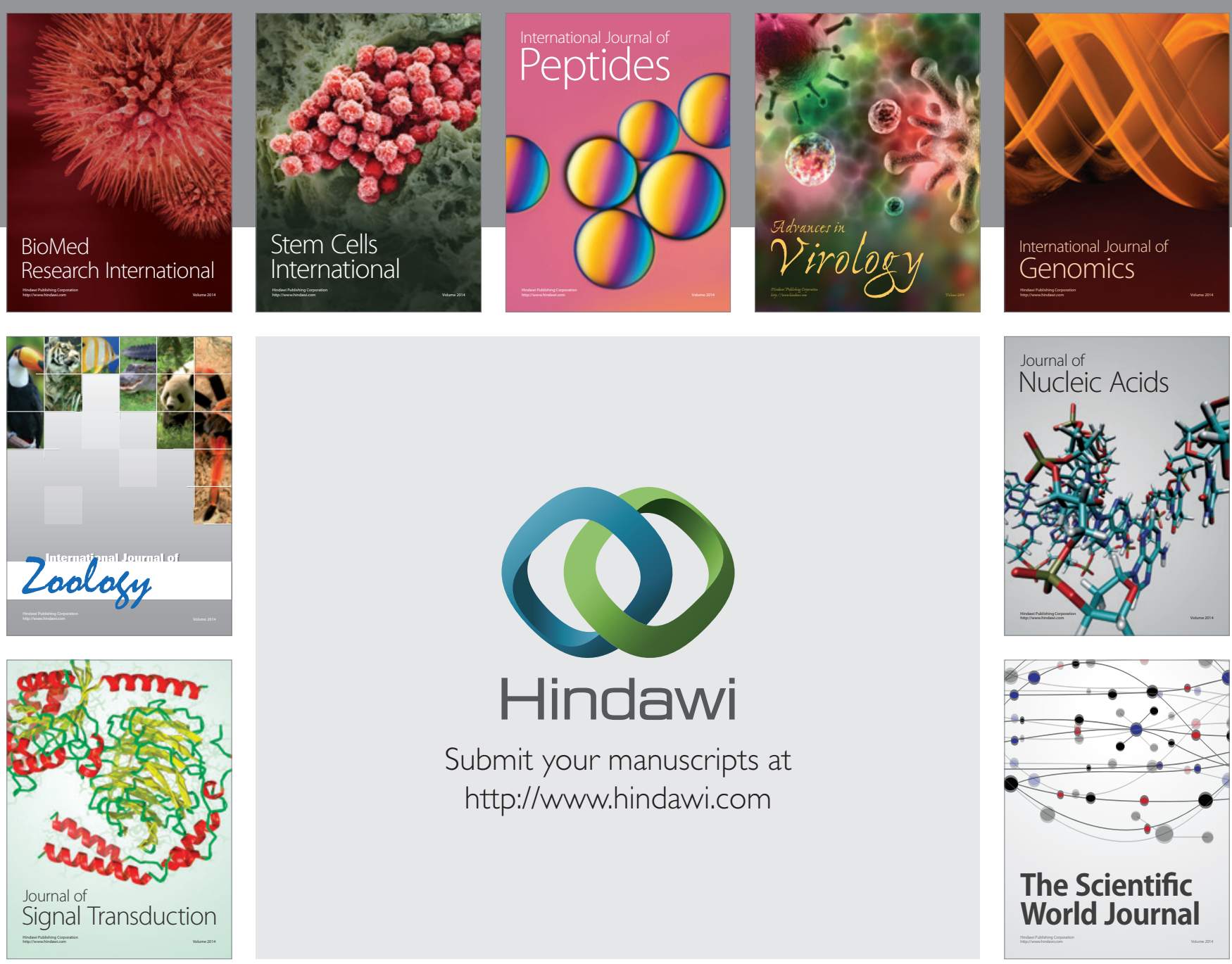

Submit your manuscripts at

http://www.hindawi.com
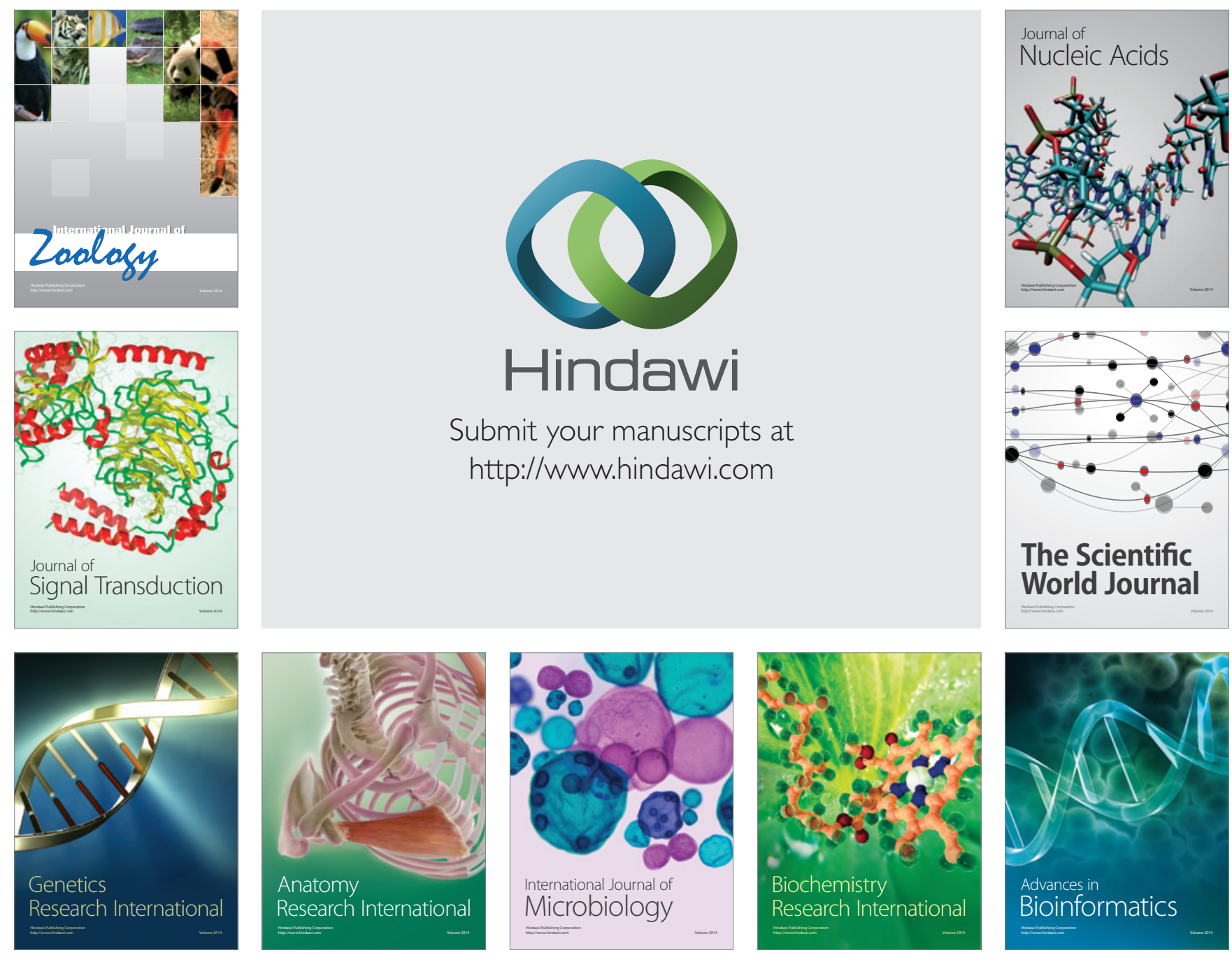

The Scientific World Journal
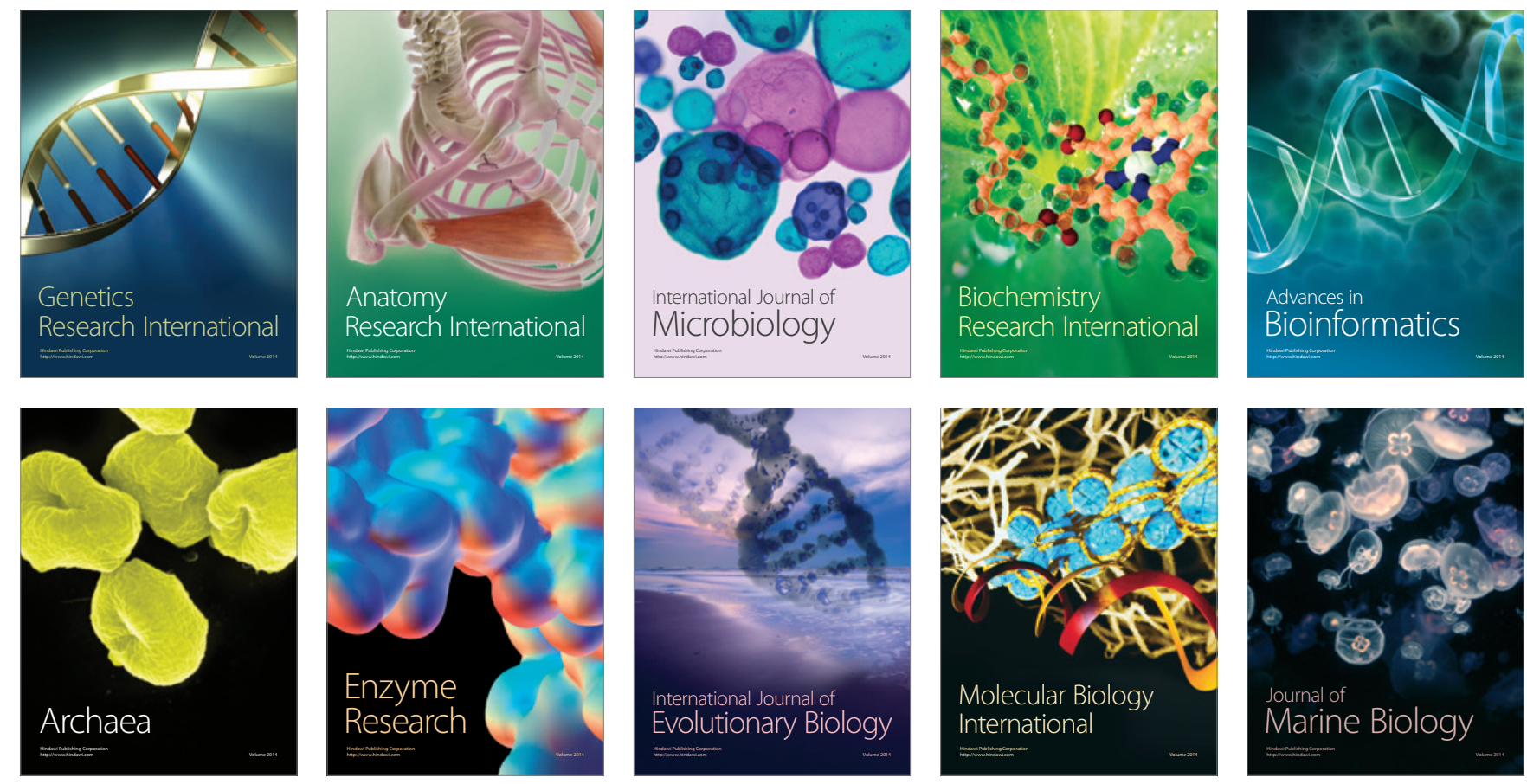